\title{
FINITE ELEMENT MICRO-MODELING FOR THE CHARACTERIZATION OF INCLINED HEAD JOINTS ARCHAEOLOGICAL MASONRY: THE CASE OF VILLA DIOMEDE IN POMPEII
}

\author{
M. Salvalaggio ${ }^{1}$, P. Roca ${ }^{2}$, M.R. Valluzzi ${ }^{3}$, F. Lorenzoni ${ }^{1}$ \\ ${ }^{1}$ University of Padova, Department of Civil, Environmental and Architectural Engineering, 35131 \\ Padova, Italy \\ e-mail: \{matteo.salvalaggio, filippo.lorenzoni\}@dicea.unipd.it \\ ${ }^{2}$ Universitat Politecnica de Catalunya, Departament d'Enginyeria de la Construcció, 08034 Barcelona, \\ Spain \\ e-mail: pere.roca.fabregat@upc.edu \\ ${ }^{3}$ University of Padova, Department of Cultural Heritage, 35139 Padova, Italy \\ e-mail: mariarosa.valluzzi@unipd.it
}

Keywords: Finite element analysis, micro modeling, nonlinear analysis, constitutive models, archaeological masonry.

\begin{abstract}
Villa Diomede is a great roman building located on the western corner of the modern archaeological site of Pompeii, built during III century BC and discovered between 1771 and 1774 during archaeological excavations. The system is composed by three levels: the road level, the garden level, which hosts the portico structure, and the underground level.

The building includes diverse types of masonry with a wide range of unit shapes, dimensions and materials (i.e. tuff, limestone, volcanic stone, clay brick etc.). Besides, an unconventional tuff masonry type was observed on some structures of the garden; it reveals inclined head joints, whose structural function is still unknown.

The paper reports the numerical micro-modeling of this particular texture of masonry, where the constitutive materials (tuff units and mortar) are discretized. The main goal of the work is the assessment of inclined masonry joints as an aseismic detail compared with widespread traditional tuff running bond masonry.

Micro models of masonry wallettes were created assigning a non-linear constitutive behavior, i.e. total strain crack model (with a parabolic behavior in compression and an exponential softening behavior in tension, whereas damage due to tensile cracking was modeled adopting a rotating crack model). Moreover, brittle 2D interfaces were modeled between mortar and units at inclined joints surfaces.

The paper focuses on numerical prediction of compressive response of masonry models subjected to uniaxial compressive tests.
\end{abstract}




\section{INTRODUCTION}

The ancient town of Pompeii was founded in VII century BC by Oscii civilization and then conquered by Romans during III century BC. Thus, it became one of the most important cities of the Campanian region, developing its urban area and economy thanks to oil and wine trade. Unfortunately, two disastrous events occurred during AD I century: the earthquake of AD 63 and the Vesuvius eruption of AD 79. The latter constituted the end of Pompeii, burying the town and conserving it until XVIII century, when archaeological excavations brought it to light. Nowadays, the archaeological site of Pompeii is probably one of the greatest examples of Roman cultural heritage, where a wide range of ancient buildings are conserved and visited by millions of people every year. Nevertheless, the importance and extension of the site require a great effort for its preservation, in which both archaeological and structural engineering fields are involved.

In this framework, Villa Diomede is a great ancient villa which arises along Via delle Tombe, on the western corner of the modern archaeological site and near the famous Villa dei Misteri (Figure 1a). It was the object of a research campaign carried out in 2015 by Ecole Normale Supérieure of Paris and the Department of Civil, Environmental and Architectural Engineering of University of Padova.

\subsection{Villa Diomede}

The building was built during III century BC and discovered during excavations of Pompeii of XVIII century (1771-1774), when a renewed interest in archaeological buildings and sites grew in Europe. Its history can be subdivided into three major periods: Pre-Roman period, Augustan period and Nero-Flavio period [1]. Modern aspect of the building is the result of transformations and events it suffered, as seismic event of AD 63, which damaged some portions of the structure and caused collapse of a part of portico structure.

The villa consists of three levels: the road level, the garden level and the underground level (Figure 1b). The road level, at the highest location, hosts the entrance, a courtyard and the main rooms of the house (e.g. kitchen, baths, bedrooms etc.). From this floor is possible to descend in the level of the garden that has a square plan on which the portico structure (i.e. quadriportico, four sided colonnade) stands. At last, the underground level (i.e. cryptoportico) constitutes the ancient cellars.

Masonry is the major structural material and it is composed of several types of resistant elements in terms of dimensions, shapes and materials, such as Neapolitan yellow tuff,

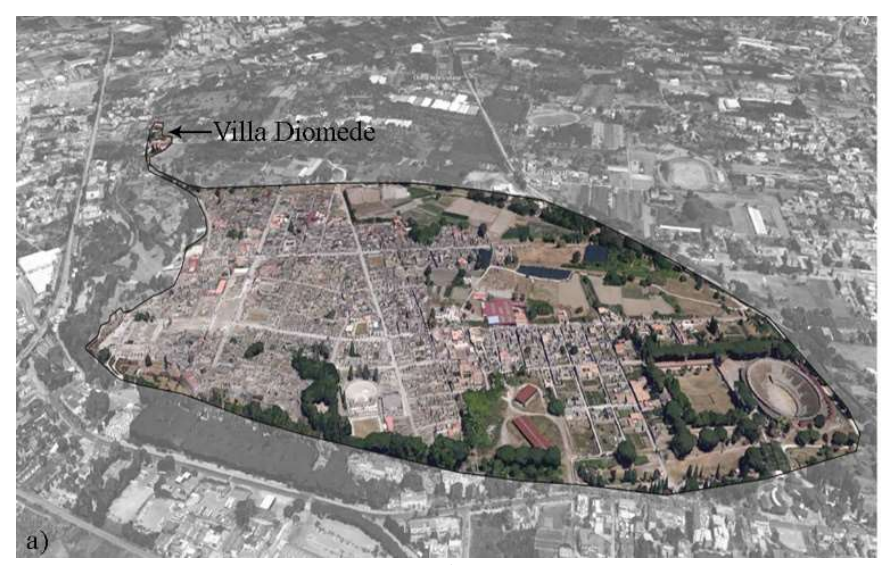

a)

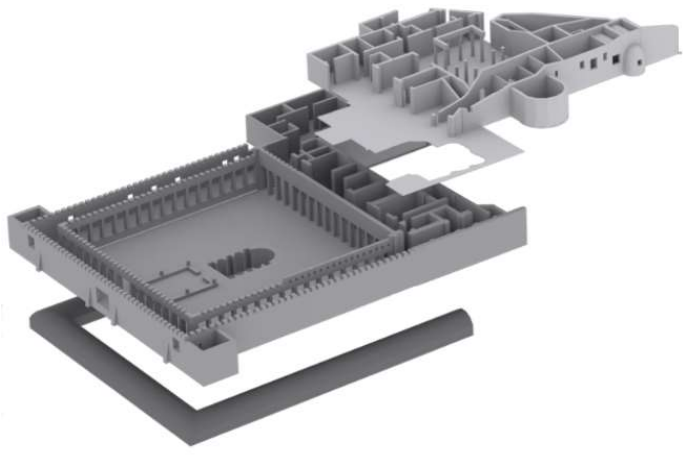

b)

Figure 1. Villa Diomede: a) location in the archaeological site of Pompeii, b) survey of the three levels. 
Nocera tuff, Sarno limestone, volcanic stone and clay brick. At road level, structural elements are often built with opus incertum and opus mixtum techniques, whereas at garden level running bond tuff masonry is the predominant construction material (Figure 2a) [3][4]. In addition, an unconventional masonry typology was observed, characterized by inclined head joints with trapezoidal and parallelogram units (Figure 2b, 2c).

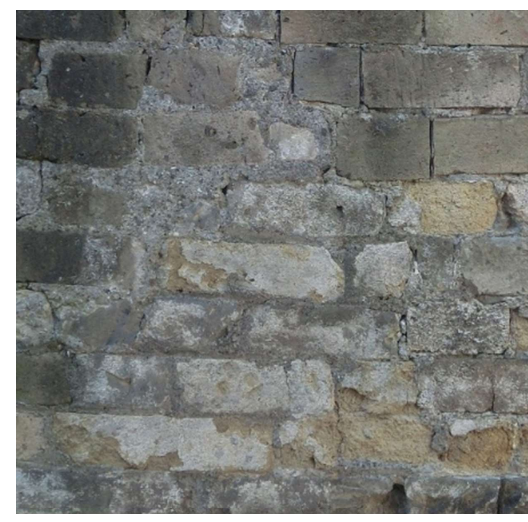

a)

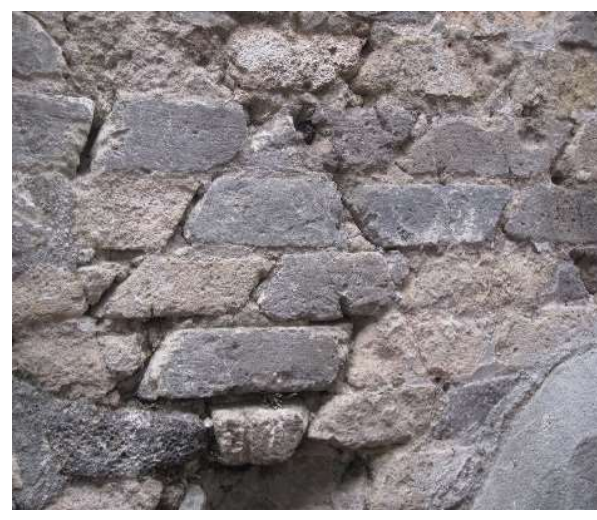

b)

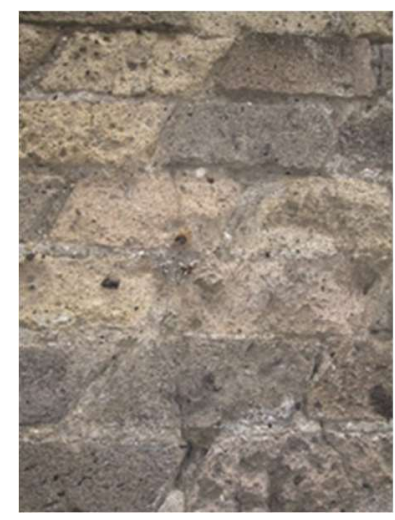

c)

Figure 2. Details of running bond tuff masonry (a), inclined head joints tuff masonry $(b, c)$

This peculiar masonry texture is located in some portions of southern colonnade pillars and perimeter walls. It was rarely encountered and its aim is still unknown: one of the possible hypothesis may be its adoption as an aseismic structural detail.

The object of the paper is the numerical characterization of the compressive behavior of insite inclined joints masonry and widespread running bond masonry. This is achieved by means of finite element analyses of representative specimens consistent with structural and geometric surveys.

\subsection{On-site inspections}

In 2015 a survey campaign was performed by the University of Padova, in which structural and geometrical information were obtained. These provided data for a critical survey map, where damage status and construction phases were reported. Most widespread damage was chemical and physical decay, which affects stone units and lime mortar, often found in a pulverized status.

Furthermore, a series of non-destructive inspections (NDT) were performed, i.e.: (i) direct sonic pulse velocity tests and sonic tomographic tests, to evaluate the status of the masonry structures, to detect internal voids and damages and to a qualitative evaluation of the masonry composition; (ii) endoscopies, applied all through the floors on existing holes, in order to measure the depth of damages and the inner masonry composition; (iii) dynamic identification tests, executed on the remaining structural elements of the villa to extract their dynamic properties.

Sonic tests reported a scarce conservative state of masonry structures, which usually are plenty of voids due to binder pulverization. The low average velocities of sonic pulse recorded on-site suggest a low quality of masonry. Endoscopic tests confirmed the presence of irregular soft stones held together by a great amount of mortar. At last, dynamic identification tests showed a global dynamic behavior of the quadriportico structure, thus suggesting a good attachment between the four colonnades. Otherwise, walls of road level showed individual behaviors, as the attachment between them is quite scarce. 


\section{MODELING STRATEGY/METHODOLOGY}

In order to perform the numerical prediction of compressive behavior of widespread masonry typologies surveyed at garden level of Villa Diomede, i.e. running bond masonry and inclined head joints masonry with tuff units and lime mortar, the following procedure was adopted:

1. Analysis of masonry textures surveyed at garden level in CAD environment;

2. Design of representative simplified geometrical models;

3. Generation of 3-D finite element micro-models of specimens;

4. Implementation of material properties provided from scientific literature;

5. Execution of uniaxial compressive test on micro-models under displacement control;

6. Sensitivity analysis performance of compressive behavior to mechanical parameters;

7. Elaboration and discussion of results.

\subsection{Geometry}

The generation of a FE micro-model requires the design of a simplified little size geometrical model able to simulate mechanical behavior of masonry components (i.e. units, mortar and their bond). Thus, masonry textures surveyed on-site were analyzed and reproduced in CAD environment, in order to extrapolate micro mechanical samples (Figure 3).
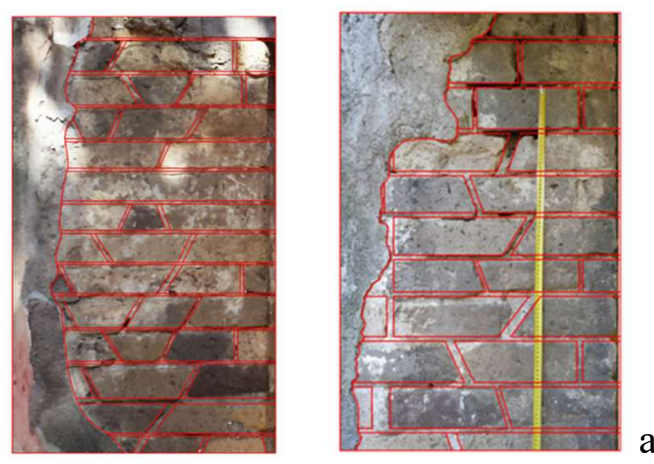

a)

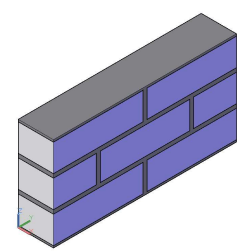

b)

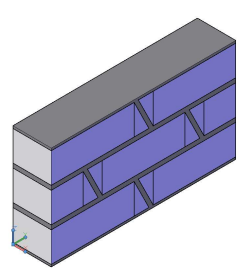

c)

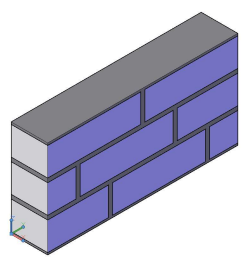

e)

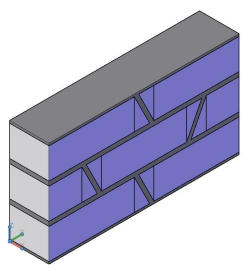

Figure 3. Scheme of geometrical micro models extrapolation. Analysis of masonry textures (a); RRB (b), IRB (c), PIJ (d), TIJ (e) geometrical samples

Two types of inclined head joints specimens and two types of running bond specimens were generated for a total of 4 models of 3 rows of units, namely:

a) Running bond masonry (RRB);

b) Irregular running bond masonry, with vertical head joint moved at the third of the brick (with the purpose to simulate irregular head joints in archaeological running bond masonry) (IRB);

c) Inclined head joints and parallelogram units (PIJ);

d) Inclined head joints and trapezoidal units (TIJ).

\subsection{FE modeling}

As micro-modeling approach the so-called meso model was adopted ([5][6]), in which units and mortar are discretized assuming a perfect bond between them. In addition, inclined bond surfaces (in inclined head joints specimens) were modeled introducing zero-thickness interface elements, whose failure occurs by separation under tension and shear slipping. 
The analyses was performed with the FE code TNO DIANA FEA 9.6 [7]: meshing process was here applied on geometrical samples in order to generate finite elements. 3-D models were generally discretized adopting 8-noded (HX24L) and 6-noded (TP18L) linear brick elements. Element size is $5 \times 5 \times 5 \mathrm{~mm}$. Besides, 8-noded interface elements Q24IF were implemented in inclined joints samples. Therefore, sample no. 1 and no. 2 were both composed by 81216 HX24L elements outlined by 22445 nodes. Sample no. 3 and no. 4 were both composed by 75024 HX24L and 1152 TP18L brick elements, while 11124 Q24IF 2-D interface elements are added at inclined surfaces.

The thickness of the specimens was halved in order to reduce computational effort, thus exploiting the existing symmetry in a single leaf masonry. Boundary conditions are the same for all models: base is fixed, whereas symmetry constraints are applied on the back surface. Lateral surfaces have no constraints, relying on low height of the model, so reducing potential buckling effect. On the top surface compressive displacement load was applied.

The four final finite element models are reported in Figure 4.

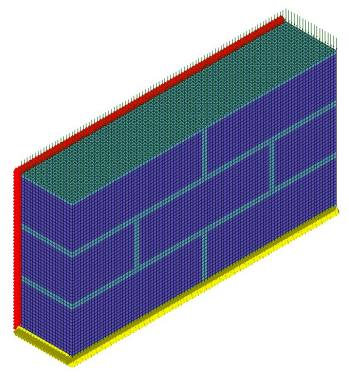

a)

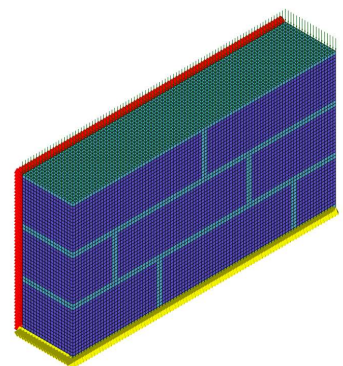

b)

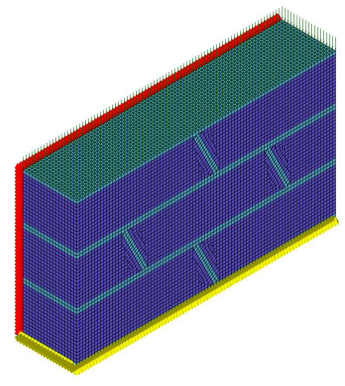

c)

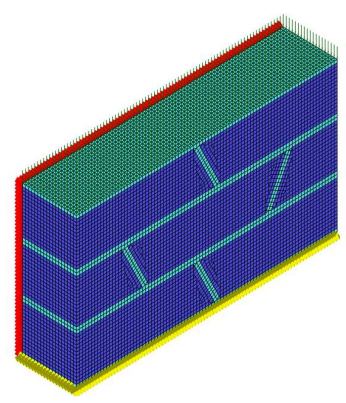

d)

Figure 4. Finite element models: regular running bond - RRB (a), irregular running bond IRB - (b), inclined head joints masonry with parallelogram units - PIJ (c), inclined head joints masonry with trapezoidal units - TIJ (d)

\subsection{Material models}

TNO DIANA permits to implement various constitutive models for compressive and tensile behaviors, i.e. the so-called total strain based crack model, which adopts a pressure dependent plasticity curve in compression and a smeared cracking model in tension, whereas tensile cracking is described by a rotating crack model.

Compressive behavior was modeled adopting a parabolic curve based on fracture energy $G_{f, c}$ [7], which is described by three characteristics strain values [9] (i.e., $\varepsilon_{\mathrm{c} / 3}, \varepsilon_{\mathrm{c}}, \varepsilon_{\mathrm{u}}$ ), as shown in Figure 5a. In addition, the increase of strength due to lateral confinement is modeled through Hsieh-Ting-Chen failure surface [10] and Selby \& Vecchio proposal [11].

Tensile behavior was modeled adopting a linear stress-strain relationship until tensile strength is reached. The post peak is described by an exponential softening curve governed by tensile fracture energy (Figure 5b). A crack bandwidth $h=(\mathrm{V})^{1 / 3}$ is assumed, where $\mathrm{V}$ is the finite element volume [11].

The shear behavior was simulated by adopting a rotating crack approach, where shear stresses at cracks are set to zero. Therefore, shear stiffness was not reduced after cracking.

The interface between units and mortar was simulated through a discrete cracking model based on a total deformation theory, where interface tensile forces are function of relative displacements and a very high normal stiffness. Elastic relationship was assumed until tensile strength peak achievement (where brittle failure occurs), with normal stiffness set to zero. As for normal stiffness, interface shear stiffness was assumed equal to zero after cracking, following a brittle behavior. 


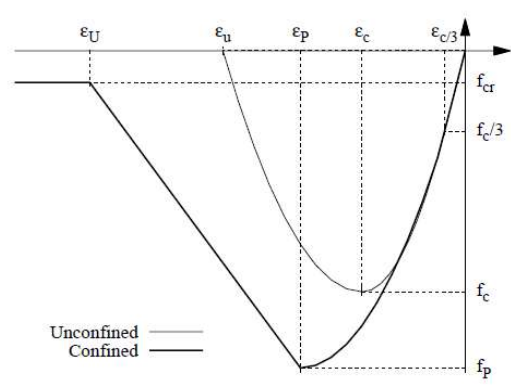

a)

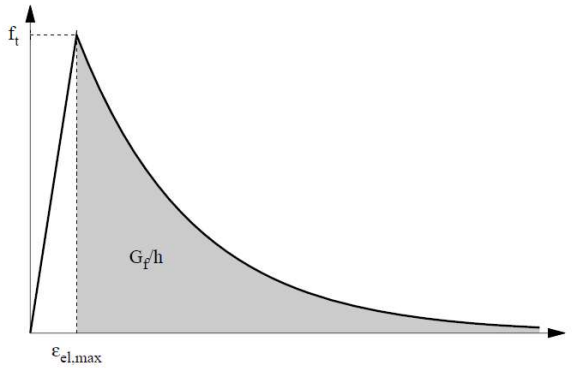

b)

Figure 5. Total strain based crack model: compressive constitutive law (a) and tensile constitutive law (b) [5].

\subsection{Assumed values}

Materials surveyed on garden level walls were mainly Neapolitan yellow tuff, Campanian grey tuff and lime mortar. Destructive tests were not allowed on the structures of Villa Diomede, thus units and binder properties were not experimentally known. Therefore, numerical values were derived from scientific literature [8].

\begin{tabular}{ccccccccccc}
\hline Element & $\begin{array}{c}\mathbf{E} \\
{[\mathbf{M p a}]}\end{array}$ & $\begin{array}{c}\mathbf{\rho} \\
{\left[\mathbf{K N} / \mathbf{m}^{3}\right]}\end{array}$ & $\mathbf{v}$ & $\begin{array}{c}\mathbf{f}_{\mathbf{c}} \\
{[\mathbf{M P a}]}\end{array}$ & $\begin{array}{c}\mathbf{G}_{\mathbf{f c}} \\
{[\mathbf{N} / \mathbf{m m}]}\end{array}$ & $\begin{array}{c}\mathbf{f}_{\mathbf{t}} \\
{[\mathbf{M P a}]}\end{array}$ & $\begin{array}{c}\mathbf{G}_{\mathbf{f t}} \\
{[\mathbf{N} / \mathbf{m m}]}\end{array}$ & $\begin{array}{c}\mathbf{E}_{\mathbf{n}, \mathbf{i}} \\
{\left[\mathbf{N} / \mathbf{m m}^{3}\right]}\end{array}$ & $\begin{array}{c}\mathbf{E}_{\mathbf{s}, \mathbf{i}} \\
{\left[\mathbf{N} / \mathbf{m m}^{3}\right]}\end{array}$ & $\begin{array}{c}\mathbf{f}_{\mathbf{t}, \mathbf{i}} \\
{[\mathbf{M P a}]}\end{array}$ \\
\hline Tuff & 1800 & 12 & 0.15 & 2.5 & 2.5 & 0.25 & 0.00625 & - & - & - \\
Mortar & 450 & 18 & 0.2 & 1.5 & 1.5 & 0.15 & 0.0025 & - & - & - \\
Interface & - & - & - & - & - & - & - & $10^{6}$ & $10^{6}$ & 0.15 \\
\hline
\end{tabular}

Table 1. Numerical materials data

\subsection{Solution method and loading}

Nonlinear analysis procedure was Secant (Quasi-Newton) with Crisfield method and a $0,1 \%$ energy norm. A Line search algorithm was also used to predict iterative displacements increments. The loading was applied as a displacement, increasing by $0.25 \mathrm{~mm}$ size steps, in order to control equivalent applying force discretization. The convergence criterion was based on displacement, force and energy for iterations check (whose maximum number was limited to 100). Parallel direct sparse solver in DIANA code was selected.

\section{RESULTS}

Current modeling strategy for compressive behavior prediction of masonry structures was validated by research work performed by Drougkas et al. [6]. The method is intended to be applied in specimens where units have a higher compressive strength and stiffness than mortar.

Numerical compressive test allows identifying material stress-strain compressive constitutive law and to extrapolate parameters such as Young's modulus, compressive strength and strain. This approach provides the identification of masonry properties from components characteristics such as materials parameters and elements shapes, by means of nonlinear structural analysis. Analyses results of the four specimens were compared to investigate the influence of the inclined joints. Finally, nonlinear sensitivity analyses were performed to generate sensitivity curves of masonry specimens and assess their global properties starting from the variation of the mechanical parameters of the constitutive materials (mortar and units). 


\begin{tabular}{cccccc}
\hline Specimen & $\mathbf{E}_{\mathrm{t}}[\mathbf{M P a}]$ & $\mathbf{E}_{\mathbf{s}}[\mathbf{M P a}]$ & $\mathbf{f}_{\mathrm{c}}[\mathbf{M P a}]$ & $\boldsymbol{\varepsilon}_{\mathrm{e}}[\mathbf{m m} / \mathbf{m m}]$ & $\boldsymbol{\varepsilon}_{\mathrm{u}}[\mathbf{m m} / \mathbf{m m}]$ \\
\hline 01_RRB & 1320 & 1220 & 2.44 & $0.177 \%$ & $0.333 \%$ \\
02_IRB & 1315 & 1220 & 2.43 & $0.177 \%$ & $0.271 \%$ \\
03_PIJ & 1300 & 1215 & 2.13 & $0.167 \%$ & $0.187 \%$ \\
04_TIJ & 1300 & 1215 & 2.12 & $0.167 \%$ & $0.187 \%$ \\
\hline
\end{tabular}

Table 2. Comparison of numerical analysis results of the four cases

\subsection{Analysis of results}

Tests results are reported in Table 2 and stress-strain curves in Figure 6a. Failure mode crack patterns of specimens are reported in Figure 6b, c, d, e.

The RRB and IRB cases revealed similar behaviors. Compressive curves showed a linear elastic behavior until $0.177 \%$ strain value and the appearance of first cracks in the head joints. At $0.25 \%$ strain value, crushed mortar joints expansion caused an increment of units stress and the damage of horizontal mortar-unit bond. Here maximum stress peak of $2.43 \mathrm{MPa}$ was reached, thus achieving maximum compressive strength of units. The post-peak behavior was different between IRB and RRB specimens: the former collapsed with a little increment (at $0.271 \%$ strain value), whereas the latter was able to keep a stable configuration until the achievement of $0.333 \%$ strain value.

Although crushing of units is not usual for running bond masonry, however it may occur and affect global collapse mode when units and mortar have comparable compressive strength [6], as in this case.

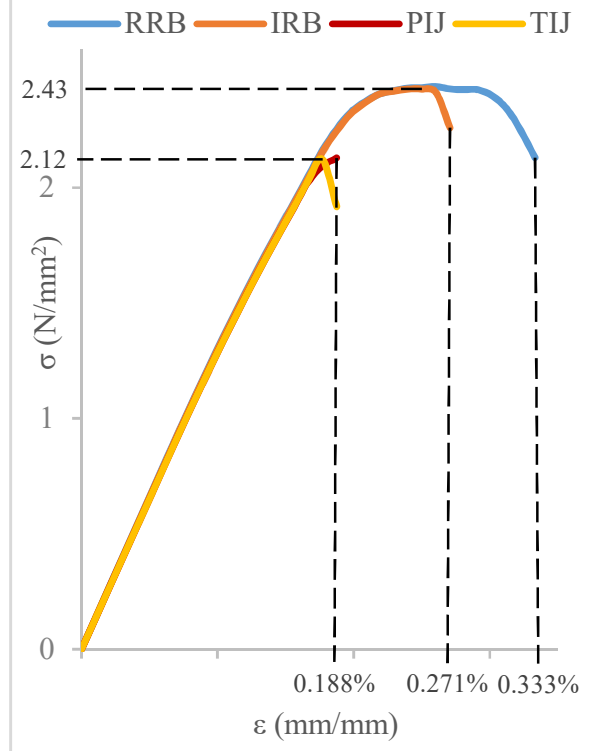

a)

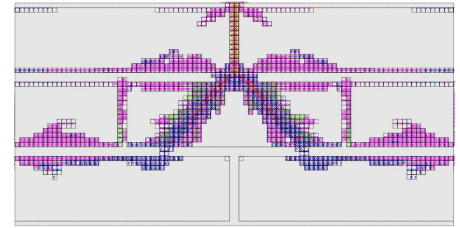

b) RRB

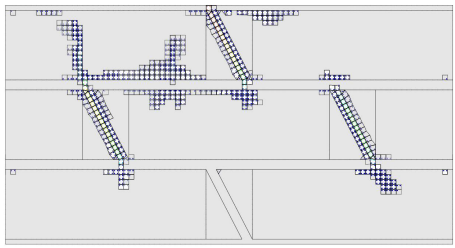

d) PIJ

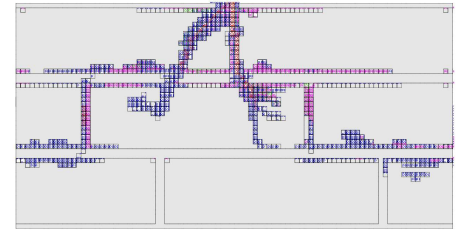

c) IRB

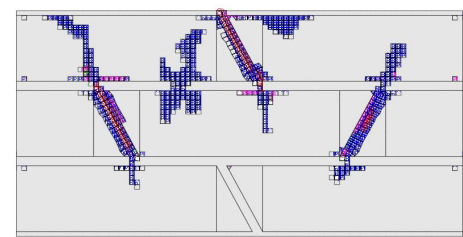

e) TIJ

Figure 6. Numerical stress-strain diagrams comparison (a). Failure mode crack status for RRB (b), IRB (c), PIJ (d), TIJ (e): blue dots indicate partially open and loading cracks, pink dots indicate partially open and unloading cracks, red dots indicate open and unloading cracks.

The PIJ and TIJ samples showed similar behaviors. Stress-strain relationship was linear until $0.167 \%$ strain value: first cracks were concentrated in inclined mortar joints and did not affect horizontal mortar-unit bond (Figure $7 \mathrm{~b}$ ). After that, units began to slide on inclined planes generated by joints' failure, so increasing stress status on adjacent (upper and lower) units and causing the vertical opening cracks passing through the thickness of the specimen. Failure 
occurred soon at $0.187 \%$ strain value, when cracks reached the whole height of the bricks (Figure 7c).

The quasi-fragile collapse mechanism observed in inclined head joints samples was thus governed by head joints, which rule cracks generation (Figure 7). On the contrary, failure mode of running bond specimens involved units strengths and allowed specimens developing their nonlinear capacity. This difference led to a reduction in terms of strain capacity and ductility in inclined head joints samples, as reported in Figure 6a.

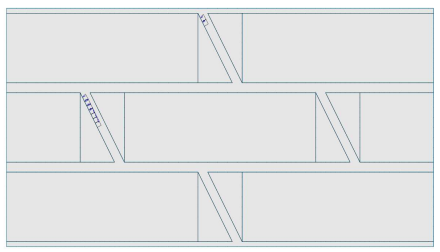

a)

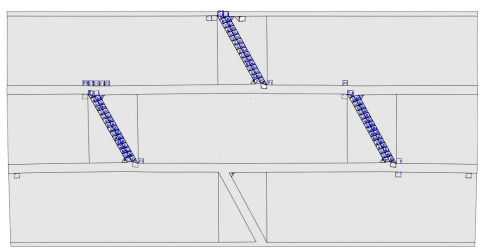

b)

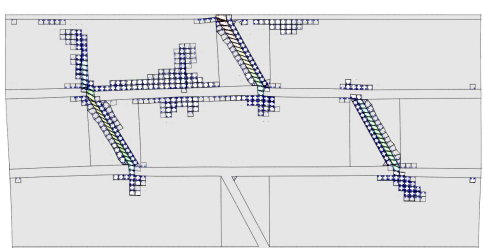

c)

Figure 7. Evolution of crack status of PIJ specimen for $0.0729 \%$ (b), $0.1458 \%$ (c) and $0.187 \%$ (d) strain values.

\subsection{Sensitivity analysis for compression test}

The lack of information about archaeological structures of Pompeii makes any numerical result subjected to wide approximation and error ranges. Thus, the relationship between masonry global properties and its components was investigated through sensitivity analysis. Numerical tests demonstrated that the mechanical properties of the components (mortar and units) have a strong influence on the global behavior.

\begin{tabular}{cccccccccc}
\hline $\begin{array}{c}\mathbf{E}_{\mathbf{u}} \\
{[\mathbf{M P a}]}\end{array}$ & $\begin{array}{c}\mathbf{E}_{\mathbf{m}} \\
{[\mathbf{M P a}]}\end{array}$ & $\begin{array}{c}\mathbf{f}_{\mathbf{c u},} \\
{[\mathbf{M P a}]}\end{array}$ & $\begin{array}{c}\mathbf{G}_{\mathbf{f c}, \mathbf{u}} \\
{[\mathbf{N} / \mathbf{m m}]}\end{array}$ & $\begin{array}{c}\mathbf{f}_{\mathbf{c m}}, \\
{[\mathbf{M P a}]}\end{array}$ & $\begin{array}{c}\mathbf{G}_{\mathbf{f c}, \mathbf{m}} \\
{[\mathbf{N} / \mathbf{m m}]}\end{array}$ & $\begin{array}{c}\mathbf{f}_{\mathbf{t u}} \\
{[\mathbf{M P a}]}\end{array}$ & $\begin{array}{c}\mathbf{G}_{\mathbf{f t}, \mathbf{u}} \\
{[\mathbf{N} / \mathbf{m m}]}\end{array}$ & $\begin{array}{c}\mathbf{f}_{\mathbf{t m}} \\
{[\mathbf{M p a}]}\end{array}$ & $\begin{array}{c}\mathbf{G}_{\mathbf{f t}, \mathbf{m}} \\
{[\mathbf{N} / \mathbf{m m}]}\end{array}$ \\
\hline 1800 & 450 & 2.5 & 2.5 & 1.5 & 1.5 & 0.25 & 0.00625 & 0.15 & 0.0025 \\
\hline 1200 & 300 & 1.8 & 1.8 & 1 & 1 & 0.1 & 0.001 & 0.10 & 0.001 \\
600 & 200 & 1.2 & 1.2 & 0.5 & 0.5 & & & & \\
\hline
\end{tabular}

Table 3. Mechanical parameters subjected to sensitivity analyses

Sensitivity analyses were performed through uniaxial compressive tests and varying the parameters reported in Table 3 . This type of analysis requires long computation time, especially if performed in nonlinear field. Thus, in order to reduce the complexity of sensitivity nonlinear problem, fracture energies were related to tensile and compressive strength, as follows:

$$
\begin{gathered}
G_{f_{c}}=d \cdot f_{c}[11] \\
G_{f t}=0.025\left(2 f_{t}\right)^{2}[12]
\end{gathered}
$$

In addition, only two most representative specimens of each typology were tested (i.e. RRB and TIJ).

One of the most interesting results were obtained for mortar compressive strength variation. In RRB specimen, a reduction in terms of ductility factor and compressive strength was observed (Figure 8a). Actually, failure mode moves to a quasi-brittle failure for mortar compressive strength decreasing (with units compressive strength kept fixed). The same variation in TIJ specimen showed a clear reduction of ultimate capacity and compressive strength (Figure 8b). 


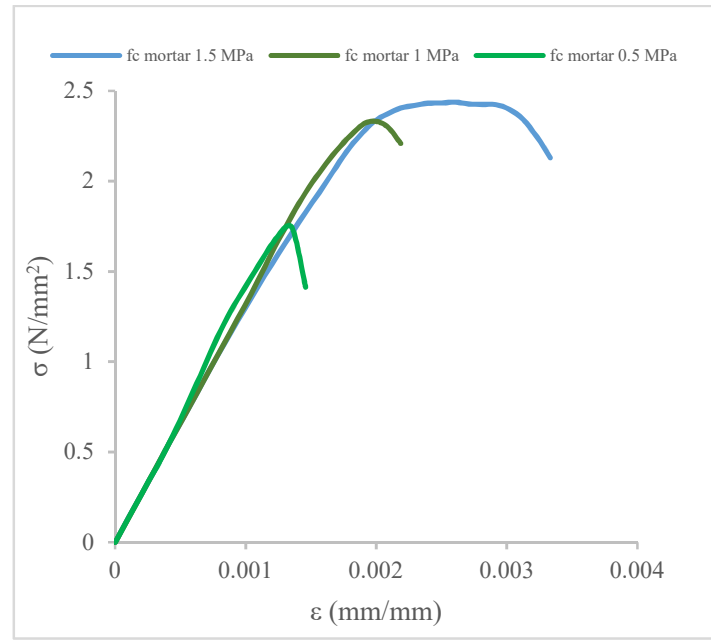

a)

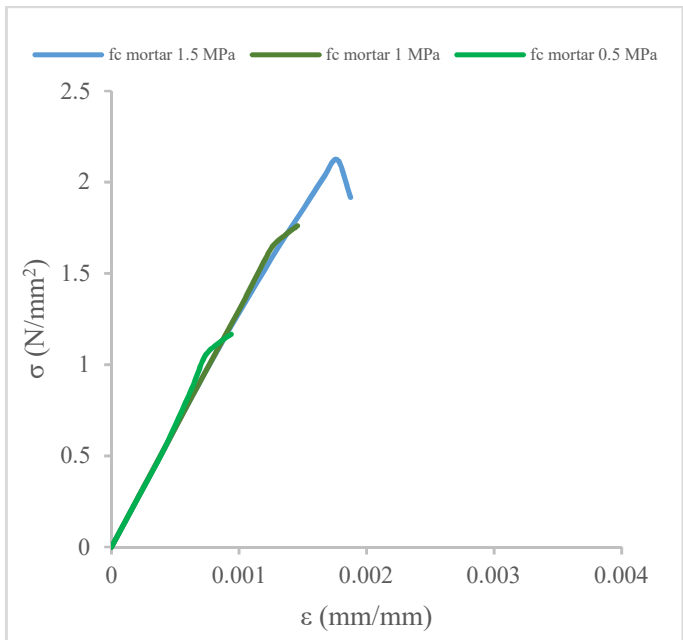

b)

Figure 8. Stress-strain relationship in function of variations of mortar compressive strength: RRB case (a) and TIJ (b)

The variation of mortar Young's modulus confirmed the main role played by head joints in inclined joints masonry failure mode: actually, the confinement effect of mortar due to the increment of its deformability was majorly enhanced in TIJ sample than RRB one, as reported in Figure 9. At mortar elasticity modulus decreasing, ultimate strains basically remained the same in RRB case, whereas in TIJ case they have a significant variation.

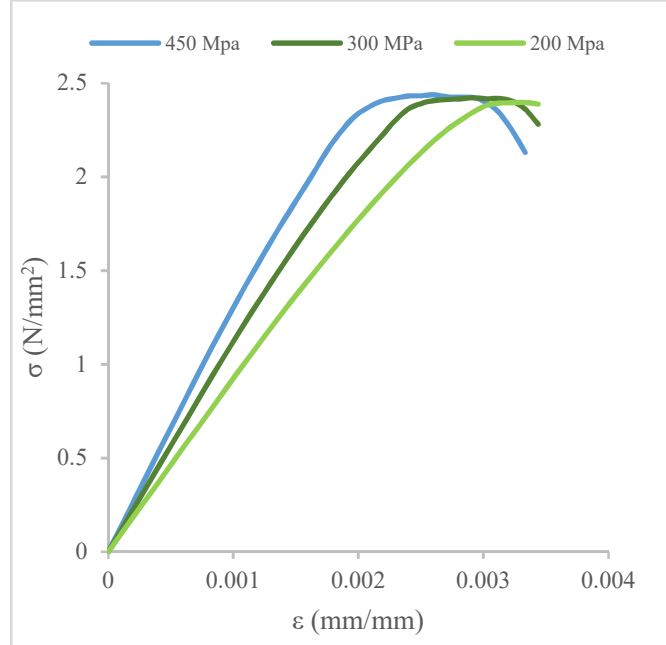

a)

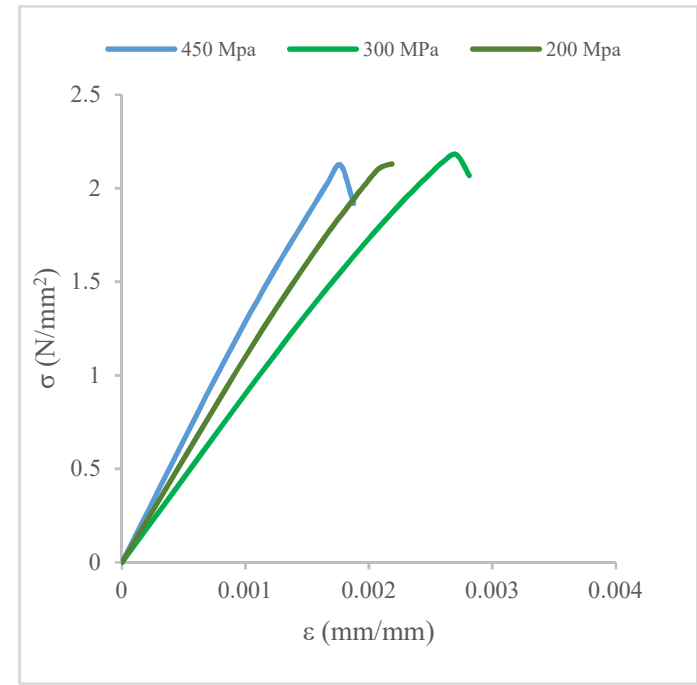

b)

Figure 9. Stress-strain relationship in function of variations of mortar Young's modulus: RRB case (a) and TIJ (b)

\section{CONCLUSIONS}

Micro mechanical finite element modeling is a powerful tool, able to simulate a wide range of masonry specimens in a relatively little computation time. Conclusions derived by numerical studies cannot be assumed as absolute statements, nevertheless their comparison with other validated numerical studies allows outlining some preliminary qualitative indications, as follows: 
- Inclined head joints masonry has minor compressive displacement capacity and compressive strength than widespread running bond;

- The closed values of mechanical parameters (e.g. compressive strength and Young's modulus) assumed by mortar and units in archaeological masonry affect the failure mode of the composite;

- The role of inclined head joints in failure mode is remarkable, thus suggesting the need of further experimental investigations.

\section{REFERENCES}

[1] A. Maiuri, L'ultima fase edilizia di Pompei, Italia romana. Campania romana. Vol II, Istituto di Studi romani, Roma, 1942

[2] H. Dessales et al., La Villa de Diomède à Pompéi. Des architectes du Grand Tour aux archéomètres d'aujourd'hui. Rapport d'activités année 2013, Projet PEPS PSL-CNRS, 2013

[3] H. Dessales et al., "Pompéi. Villa Diomède. Campagne d'étude 2014", Cronique des activités archéologiques de l'Ecole francaise de Rome, 2015

[4] A. Sogliano, Pompei preromana dalle origini all'80 a.C., Pompei nel suo sviluppo storico Vol. 1, Athenaeum, Roma, 1937

[5] A. Drougkas, Derivation of the properties of masonry through micro-modeling technique. PhD Thesis. Director: Roca P., Mollins C., Universitat Politecnica de Catalunya, 2015

[6] A. Drougkas, P. Roca, C. Molins, "Numerical prediction of the behavior, strength and elasticity of masonry in compression”, Engineering Structures, No. 90, 2015, pp. 15-28

[7] TNO Diana, DIANA 9.6 Finite Element Analysis User Guide, TNO DIANA BV, Delft, 2014

[8] Ceroni F., Pece M., Manfredi G., Marcari G., Voto S., "Analisi e caratterizzazione meccanica di murature di tufo", Estratto dagli atti del $15^{\circ}$ Congresso C.T.E. (Bari, 46.10.2004), 2006

[9] P. H. Feenstra, Computational Aspects of Biaxial Stress in Plain and Reinforced Concrete. PhD Theis, Delft University of Technology, 1993

[10] S. S. Hsieh, E. C. Ting, W. F. Chen, A plastic-fracture model for concrete, Int J Solids Struct, 18:181-97, 1982

[11] R. G. Selby, F. J. Vecchio, Three-dimensional Constitutive Relations for Reinforced Concrete. Tech Rep. 93-02, University of Toronto, Department of Civil Engineering, Toronto, Canada, 1993

[12] CEN, EN 1996-1-1: rules for reinforced and unreinforced masonry, 2005 